\title{
MicroRNA-665 regulates the proliferation, apoptosis and adhesion of gastric cancer cells by binding to cadherin 3
}

\author{
XINHUI FANG, YANGQIU BAI, LIDA ZHANG and SONGZE DING \\ Department of Gastroenterology and Hepatology, Henan Provincial People's Hospital, \\ People's Hospital of Zhengzhou University, School of Clinical Medicine, Henan University, \\ Zhengzhou, Henan 450003, P.R. China
}

Received September 11, 2020; Accepted March 23, 2021

DOI: $10.3892 / \mathrm{ol} .2021 .12755$

\begin{abstract}
Numerous studies have reported that abnormal cadherin 3 (CDH3) and microRNA (miRNA/miR)-665 expression can induce the progression of gastric cancer (GC). However, the mechanism of interaction between miR-665 and $\mathrm{CDH} 3$ in GC requires further investigation. The present study aimed to investigate the influence of miR-665 and $\mathrm{CDH} 3$ in GC development. The effect of miR-665 and CDH3 on GC tissues and cell lines was examined using reverse transcription-quantitative PCR. Subsequently, CDH3 protein expression in $\mathrm{GC}$ cell lines was detected using western blotting. To confirm the association between miR-665 and $\mathrm{CDH} 3$, a dual-luciferase reporter assay system was employed. Cell proliferation and adhesion were analyzed using BrdU ELISA, MTT and cell adhesion assays. Finally, caspase-3 activity assay kit and FITC apoptosis detection kit were used for the determination of apoptosis of GC cells. The current findings confirmed the upregulation of $\mathrm{CDH} 3$ expression in $\mathrm{GC}$ cell lines and tissues. Experimental results indicated that $\mathrm{CDH} 3$ overexpression increased cell proliferation and adhesion, but decreased the apoptosis level of the cells. Similarly, the miR-665 inhibitor enhanced cell proliferation and adhesion, but inhibited apoptosis of GC cells. Additionally, it was observed that $\mathrm{CDH} 3$ was a direct target of miR-665 in GC cells and that miR-665 inhibited $\mathrm{CDH} 3$ expression, thereby repressing the progression of GC. In conclusion, the present study suggested that by targeting $\mathrm{CDH} 3$, miR-665 suppressed the progression of GC. These findings may provide a significant theoretical basis for future GC clinical therapy.
\end{abstract}

Correspondence to: Dr Songze Ding, Department of Gastroenterology and Hepatology, Henan Provincial People's Hospital, People's Hospital of Zhengzhou University, School of Clinical Medicine, Henan University, 7 Wei Wu Road, Jin Shui, Zhengzhou, Henan 450003, P.R. China

E-mail: songze_Ding@163.com

Key words: microRNA-665, cadherin 3, gastric cancer, proliferation, apoptosis, adhesion

\section{Introduction}

Gastric cancer (GC) refers to the deleterious inflammation of the stomach wall, and this type of tumor accounted for $\sim 8.2 \%$ of tumor-associated deaths worldwide in 2018 (1). GC is a multifactorial disease that is associated with the environment, including Helicobacter pylori infection (2), smoking and alcohol consumption (3). To date, treatment options such as surgery, radiotherapy, chemotherapy and medication are the most frequently therapeutic strategies for patients with GC; however, these methods have not improved the recurrence and the poor prognosis of GC (4). Gene therapy has also been utilized in recent years to treat patients with GC (5). However, numerous target genes in GC remain unknown. By exploring the molecular mechanism of $\mathrm{GC}$, the clinical outcomes of patients suffering from GC can be improved.

The cadherin $3(\mathrm{CDH} 3)$ gene is located on chromosome $16 \mathrm{q} 22.1$ and consists of 18 exons. It is found in a six-cadherin bundle, and this calcium-dependent gene is comprised of five extracellular repeats, a cytoplasmic tail and a transmembrane region (6). The aberrant expression of $\mathrm{CDH} 3$ has been frequently observed in various types of cancer, including colorectal (7), pancreatic (8) and esophageal cancer (9). More specifically, $\mathrm{CDH} 3$ has been demonstrated to increase cell adhesion and invasion (10). However, only a few studies have been conducted to investigate the tumorigenic role of $\mathrm{CDH} 3$ in GC cells $(11,12)$, revealing that $\mathrm{CDH} 3$ expression was upregulated in GC tissues. Therefore, it is noteworthy to investigate the impacts of $\mathrm{CDH} 3$ on $\mathrm{GC}$.

MicroRNAs (miRNAs/miRs) can be referred to as non-coding protein sequences with the capability of regulating, decoding and controlling gene expression (13). Previous studies have revealed that miRNAs regulate cell proliferation, invasion and apoptosis, as well as serving a pivotal role in tumor progression $(14,15)$. For instance, miR-665 has been associated with lung cancer progression by increasing cell proliferation, migration and invasion (16). Some studies have suggested that miR-665 may be used as a potential molecular target for various types of cancer, including pancreatic (17), breast (18) and ovarian carcinoma (19). Additionally, several studies on GC have suggested that by targeting different genes, miR-665 may act both as an oncogene and as a tumor inhibitor $(20,21)$. 
However, the mechanism of interaction between miR-665 and $\mathrm{CDH} 3$ in $\mathrm{GC}$ requires further investigation.

The present study aimed to explore the effect of the miR-665/CDH3 interactome on the pathogenesis of GC. The objective included the investigation of potential bio-targets for GC treatment. It was hypothesized that miR-665 could suppress GC cells by targeting $\mathrm{CDH} 3$. The current study may be relevant in terms of providing a theoretical basis for $\mathrm{GC}$ clinical therapy.

\section{Materials and methods}

Bioinformatics analysis. The mRNA expression profiles GSE118916 (22) and GSE79973 (23) were obtained from the Gene Expression Omnibus (GEO) database (https://www. ncbi.nlm.nih.gov/gds/?term=), a public database that stores gene expression microarrays. The upregulated differentially expressed genes (DEGs) were screened from GSE118916 and GSE79973 using $\log 2$-fold-change $(\log F C)>1$ and adjusted (adj) $\mathrm{P}<0.05$. STRING (https://string-db.org/) was used to analyze the Gene Ontology (GO) enrichment of the upregulated DEGs. The expression levels of the key genes in stomach adenocarcinoma (STAD) were analyzed using The Cancer Genome Atlas (TCGA) database (https://portal.gdc.cancer.gov/).

Clinical samples and cell lines. All tissue samples, including tumor and non-tumor specimens, were obtained from 30 patients with GC (16 male and 14 female; median age, 60 years; age range 29-72 years) at Henan Provincial People's Hospital (Zhengzhou, China) between January 2019 and January 2020. All patients signed informed consent forms to participate in the study. The ethical protocols of the present study were approved by the Ethics Committee of Henan Provincial People's Hospital. The diagnosis of GC included a clinical examination, blood sampling, endoscopy (when clinically indicated) and computed tomography scanning of the chest, abdomen and pelvis. The tumor tissues were all confirmed by endoscopic biopsy or surgical specimens. Patients with a history of cancer or severe clinical symptoms and genetic diseases, and patients who received preoperative radiochemotherapy were excluded from the study. Non-tumor specimens were $\geq 1.5 \mathrm{~cm}$ from the tumor margins. All collected samples were stored at the recommended temperature $\left(-80^{\circ} \mathrm{C}\right)$. The clinical features of patients who participated in the study are shown in Table I. The tumors were staged following the tumor-node-metastasis (TNM) staging system of the International Union Against Cancer (24). CDH3 was divided into high and low expression groups according to the median expression level of $\mathrm{CDH} 3$ (5.848). The association between $\mathrm{CDH} 3$ expression and clinical characteristics in patients with GC are shown in Table SI.

All cell lines used were purchased from the American Type Culture Collection, including GC cell lines (HGC-27, GTL-16, MKN74 and AGS) and the gastric epithelial cell line (GES-1). MKN74 cells were maintained in F-12K medium, GES-1 cells were maintained in RPMI-1640 medium and AGS, HGC-27 and GTL-16 cells were kept in DMEM (Gibco; Thermo Fisher Scientific, Inc.). The media were supplemented with $100 \mathrm{U} / \mathrm{ml}$ penicillin and 10\% FBS (Gibco; Thermo Fisher Scientific, Inc.). Cells were incubated at $37^{\circ} \mathrm{C}$ in an atmosphere containing $5 \% \mathrm{CO}_{2}$.
$R N A$ extraction and reverse transcription-quantitative ( $R T-q)$ $P C R$. RNA extraction from tissues and cells was performed using TRIzol ${ }^{\circledR}$ reagent (Invitrogen; Thermo Fisher Scientific, Inc.). cDNA was obtained using the PrimeScript First Strand cDNA Synthesis kit (Takara Bio, Inc.) according to the manufacturer's protocol. Subsequently, qPCR was performed using SYBR ${ }^{\circledR}$ Premix Ex Taq ${ }^{\mathrm{TM}}$ (Takara Bio, Inc.) according to the manufacturer's protocol. The thermocycling conditions were as follows: Denaturation at $95^{\circ} \mathrm{C}$ for $20 \mathrm{sec}$, followed by 40 cycles of denaturation at $95^{\circ} \mathrm{C}$ for $1 \mathrm{~min}$ and annealing/extension at $60^{\circ} \mathrm{C} 20 \mathrm{sec}$. The expression levels of miR-665, CDH3, collagen type XVIII $\alpha 1$ chain (COL18A1) and fibroblast activation protein (FAP) were measured using the $2^{-\Delta \Delta \mathrm{Cq}}$ method, and U6 or GAPDH were used as an endogenous reference for miRNA or mRNA, respectively. The relative expression levels of miR-665, CDH3, COL18A1 or FAP were reported in relation to an internal control gene called $\Delta \mathrm{Ct}$. The $\Delta \mathrm{CT}$ and $\Delta \Delta \mathrm{CT}$ values were calculated using the following mathematical formulas: $\Delta \mathrm{Ct}=\mathrm{Ct}_{\text {miRNA-126/CDH3 }}-\mathrm{Ct}_{\mathrm{U} 6 / \mathrm{GAPDH}}$ and $\Delta \Delta \mathrm{Ct}=\Delta \mathrm{Ct}_{\text {case }}-\Delta \mathrm{Ct}_{\text {control }}$ (25). All the primer sequences used in the study are listed in Table II.

Western blotting. GC cells were lysed using RIPA lysis buffer (Sangon Biotech Co., Ltd.). Total protein concentration was quantified using the BCA method. Proteins (30 $\mu \mathrm{g} /$ lane) were separated via $10 \%$ SDS-PAGE and then transferred to PVDF membranes, which were blocked with 5\% BSA (Gibco; Thermo Fisher Scientific, Inc.) for $2 \mathrm{~h}$ at $25^{\circ} \mathrm{C}$, and washed three times with TBS-0.1\% Tween-20. After blocking the membranes, primary antibodies against CDH3 (1:1,000; cat. no. ab242060; Abcam) and GAPDH (1:2,000; cat. no. ab181602; Abcam) were used to incubate the membranes overnight at $4^{\circ} \mathrm{C}$. Subsequently, HRP-conjugated goat anti-rabbit IgG (1:5,000; cat. no. ab97051; Abcam) secondary antibody was incubated for $1 \mathrm{~h}$ at $25^{\circ} \mathrm{C}$. The protein signal was subsequently visualized using an ECL system (Bio-Rad Laboratories, Inc.). Finally, the quantification of the density of each band was performed using Gel-Pro Analyzer 4.0 (Media Cybernetics, Inc.).

Cell transfection. The small interfering RNA (siRNA) used as a non-targeting negative control (si-NC) and the siRNA against CDH3 (si-CDH3) were obtained from Shanghai Tuoran Biological Technology Co., Ltd. For CDH3 overexpression, full-length $\mathrm{CDH} 3$ was synthesized and transformed into pcDNA3.1 (OE-CDH3), provided by Shanghai Tuoran Biological Technology Co., Ltd., and the corresponding empty vector was used as a NC (OE-NC). Using Lipofectamine ${ }^{\circledR} 3000$ Transfection Reagent (Invitrogen; Thermo Fisher Scientific, Inc.), the transfection of AGS and HGC-27 cells was performed using $50 \mathrm{nM}$ siRNA or $2 \mu \mathrm{g} / \mathrm{ml}$ pcDNA3.1 in 24-well plates at $37^{\circ} \mathrm{C}$ for $48 \mathrm{~h}$. Subsequent experiments were performed $48 \mathrm{~h}$ after transfection. The next procedure involved the selection of stable cell lines with puromycin $(4 \mu \mathrm{g} / \mathrm{ml})$. Additionally, the miR-665 inhibitor, miR-665 mimic and the corresponding non-targeting NCs (mimic-NC and inhibitor-NC) were obtained from Genewiz, Inc. The sequences of si-CDH3, miR-665 inhibitor, miR-665 mimic and their corresponding NCs are listed in Table III. HGC-27 and AGS cells were seeded into 24 -well plates $\left(2 \times 10^{5}\right.$ cells/well). After the density of the cells was $50 \%$, they were transfected with the miR-665 mimic, miR-665 inhibitor or corresponding negative controls 
Table I. Clinical characteristics of 30 patients with gastric cancer.

\begin{tabular}{|c|c|c|}
\hline Characteristics & $\mathrm{N}$ & Percentage, $\%$ \\
\hline \multicolumn{3}{|l|}{ Age, years } \\
\hline$>60$ & 18 & 60.0 \\
\hline$\leq 60$ & 12 & 40.0 \\
\hline \multicolumn{3}{|l|}{ Sex } \\
\hline Male & 16 & 53.3 \\
\hline Female & 14 & 46.7 \\
\hline \multicolumn{3}{|l|}{ Tumor size, cm } \\
\hline$>5$ & 19 & 63.3 \\
\hline$\leq 5$ & 11 & 36.7 \\
\hline \multicolumn{3}{|c|}{ Histological grade } \\
\hline Low & 13 & 43.3 \\
\hline High & 17 & 56.7 \\
\hline \multicolumn{3}{|l|}{ TNM stage } \\
\hline I & 5 & 16.7 \\
\hline II & 7 & 23.3 \\
\hline III & 14 & 46.7 \\
\hline IV & 4 & 13.3 \\
\hline \multicolumn{3}{|c|}{ Lymph nodes status } \\
\hline Positive & 19 & 63.3 \\
\hline Negative & 11 & 36.7 \\
\hline \multicolumn{3}{|l|}{ Differentiation } \\
\hline Poor & 17 & 56.7 \\
\hline Well/moderate & 13 & 43.3 \\
\hline
\end{tabular}

Table II. Primer sequences used for reverse transcription-quantitative PCR.

\begin{tabular}{|c|c|}
\hline Gene & Primer sequences $\left(5^{\prime}-3^{\prime}\right)$ \\
\hline \multirow[t]{2}{*}{$\operatorname{miR}-665$} & Forward: GCCGAGACCAGGAGGCUGA \\
\hline & Reverse: CTCAACTGGTGTCGTGGA \\
\hline \multirow[t]{2}{*}{ U6 } & Forward: ATTGGAACGATACAGAGAAGATT \\
\hline & Reverse: GGA ACGCTTCACGAATTTG \\
\hline \multirow{2}{*}{$\mathrm{CDH} 3$} & Forward: CAGGTGCTGAACATCACGGACA \\
\hline & Reverse: CTTCAGGGACAAGACCACTGTG \\
\hline \multirow{2}{*}{ COL18A1 } & Forward: GGAGAGATTGGCTTTCCTGGAC \\
\hline & Reverse: CCTCATGCCAAATCCAAGGCTG \\
\hline \multirow[t]{2}{*}{ FAP } & Forward: GGAAGTGCCTGTTCCAGCAATG \\
\hline & Reverse: TGTCTGCCAGTCTTCCCTGAAG \\
\hline \multirow[t]{2}{*}{ GAPDH } & Forward: AGCCACATCGCTCAGACAC \\
\hline & Reverse: GCCCAATACGACCAAATCC \\
\hline
\end{tabular}

miR, microRNA; CDH3, cadherin 3; COL18A1, collagen type XVIII $\alpha 1$ chain; FAP, fibroblast activation protein.

at a concentration of $50 \mathrm{nM}$ using Lipofectamine 3000 Transfection Reagent for $48 \mathrm{~h}$ at $37^{\circ} \mathrm{C}$. Subsequent experiments were performed $48 \mathrm{~h}$ after transfection.
MTT assay. MTT colorimetric assay was used to detect cell viability. HGC-27 and AGS cells were cultured into 96-well plates at a density of $5 \times 10^{3}$ cells/well. MTT $(5 \mathrm{mg} / \mathrm{ml})$ was then added to each well at four time points $(0,24,48$ and $72 \mathrm{~h})$. After $4 \mathrm{~h}$ incubation at $37^{\circ} \mathrm{C}$, acid isopropanol was added to each well. The cell samples were then mixed until the dark blue crystals dissolved completely. A microplate reader was used to read the absorbance at $570 \mathrm{~nm}$. The triplicate repeated readings for each sample were averaged, and the medium background was subtracted from the analytical readings to correct the absorbance.

BrdU ELISA assay. The BrdU Cell Proliferation Assay kit (cat. no. 6813; Cell Signaling Technology, Inc.) was used to detect cell proliferation according to the manufacturer's protocol. First, $2 \times 10^{4}$ HGC-27 and AGS cells were cultured into each well of a 96-well plate. The next day, the cells were serum-starved overnight. Subsequently, the serum was added to the cells for $8 \mathrm{~h}$. After that, cells were incubated for 8-12 h without removing the treatment media. The absorbance value was subsequently recorded at $450 \mathrm{~nm}$ using a microplate reader. BrdU was incorporated into the DNA of dividing cells, and the intensity of the luminescence recorded using a microplate reader was proportional to the amount of incorporated BrdU in the cells to evaluate cell proliferation.

Apoptosis assay. The FITC Annexin V Apoptosis Detection kit (BD Biosciences) was used for apoptosis analysis according to the manufacturer's protocol. After the cell lines were collected

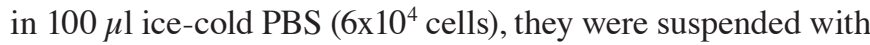
the binding buffer $(100 \mu \mathrm{l})$ and treated with Annexin V-FITC $(5 \mu \mathrm{l})$ and propidium iodide $(5 \mu \mathrm{l})$ in the dark at $20-22^{\circ} \mathrm{C}$ for $15 \mathrm{~min}$. The next procedure was the addition of $400 \mu \mathrm{l}$ of the same binding buffer to the aforementioned binding buffer $(100 \mu \mathrm{l})$. The cells were detected and characterized by flow cytometry (FACSCalibur; Becton, Dickinson and Company), and cells were analyzed using FlowJo v10.6.2 (FlowJo LLC). Early apoptosis (Annexin V-FITC ${ }^{+} / \mathrm{PI}^{-}$; Q4) and late apoptosis (Annexin V-FITC $/ \mathrm{PI}^{+}$; Q2) were considered as the apoptosis rate.

Caspase activity assay. This assay was performed using the caspase-3 activity assay kit (cat. no. 5723; Cell Signaling Technology, Inc.) according to the manufacturer's protocol. The first step was seeding AGS and HGC-27 cells into the 96-well plates $\left(2 \times 10^{4}\right.$ cells/well) and culturing the cells at the suggested operating conditions $\left(37^{\circ} \mathrm{C}\right.$ and $80 \%$ density). The caspase- 3 assay loading solution was then prepared by adding N-Acetyl-Asp-Glu-Val-Asp-p-Nitroanilide (DEVD-pNA) substrates and DL-Dithiothreitol (DTT) reagents. This preparation was performed according to the manufacturer's instructions. After the cells were collected, they were suspended with ice-cold cell lysis buffer included in the aforementioned kit for $10 \mathrm{~min}$ and then incubated on ice. Then, the caspase-3 assay loading solution (100 $\mu \mathrm{l} /$ well) was added to the cells, and the mixture was incubated at $37^{\circ} \mathrm{C}$ for $2 \mathrm{~h}$. The absorbance at $405 \mathrm{~nm}$ was measured using a microplate reader.

Cell adhesion assay. HGC-27 and AGS cells were transferred to a DMEM containing 10\% FBS and seeded into 96-well 
Table III. Oligonucleotide sequences used for cell transfection.

Oligonucleotide

Primer sequences (5'-3')

si-CDH3

si-NC

Forward: UUCAACAGCAACCAGCCUGUUUCCU

Reverse: AGGAAACAGGCUGGUUGCUGUUGAA

Forward: CGGAAGGCCUAAUGCCGAAdTdT

miR-665 inhibitor

Reverse: UUCGGCAUUAGGCCUUCCGdTdG

inhibitor-NC

AGGGGCCUCAGCCUCCUGGU

miR-665 mimic

CAGUACUUUUGUGUAGUACAA

Forward: CAGCAGCACACUGUGGUUUGU

mimic-NC

Reverse: AGGGACCUCAGCCUCCUGGUUU

Forward: UUCUCCGAACGUGUCACGUTT

Reverse: ACGUGACACGUUCGGAGAATT

si, small interfering RNA; CDH3, cadherin 3; NC, negative control; miR, microRNA.

plates $\left(2 \times 10^{4}\right.$ cells/well). A total of $\sim 30 \mu \mathrm{l} /$ well of Collagen I solution $(40 \mu \mathrm{g} / \mathrm{ml})$ (Chrono-log Corporation) was transferred to the 96 -well plate and incubated at $4^{\circ} \mathrm{C}$ for $12 \mathrm{~h}$. The next step was the removal of the solution, followed by air-drying the plate at $20-22^{\circ} \mathrm{C}$. The cells were then washed with serum-free DMEM and cultured for $8 \mathrm{~h}$ at $37^{\circ} \mathrm{C}$ in serum-free DMEM. To dissociate them, $10 \mathrm{mM}$ EDTA was added to the cells for $10 \mathrm{~min}$ at $25^{\circ} \mathrm{C}$. The cells were then washed three times with PBS to remove EDTA and were suspended in DMEM with $0.1 \%$ BSA $\left(2 \times 10^{5}\right.$ cells $/ \mathrm{ml}$; Gibco; Thermo Fisher Scientific, Inc.). Subsequently, $100 \mu 1$ cell suspension was added to the 96-well plate with air-dried Collagen I, and the cells were incubated at $37^{\circ} \mathrm{C}$ for $60 \mathrm{~min}$. After the cells adhered to the plate surface, DMEM (100 $\mu \mathrm{l})$ was added to eliminate other non-adherent cells. Next, the cells were incubated at $37^{\circ} \mathrm{C}$ for $1 \mathrm{~h}$ with DMEM containing 10\% FBS. Subsequently, the MTT substrate $(10 \mu \mathrm{l})$ was added to each well, and the cells were incubated for $2 \mathrm{~h}$ at $30^{\circ} \mathrm{C}$. DMSO $(100 \mu \mathrm{l})$ was then added to lyse the cells. Finally, the absorbance was measured at $570 \mathrm{~nm}$ using a microplate reader. The absorbance was positively associated with the number of adherent cells, so the optical density value was used to evaluate the adhesion ability of cells.

Luciferase assay. The miRNA upstream of CDH3 was predicted using bioinformatics softwares, including GSE93415 (26) from Gene Expression Omnibus DataSets (https://www.ncbi.nlm.nih.gov/gds/?term=), TargetScan (http://www.targetscan.org/), starBase (http://starbase.sysu. edu.cn/panCancer.php) and Venny 2.1.0 (http://bioinfogp.cnb. csic.es/tools/venny/index.html). The pmiRGLO plasmid vector (Promega Corporation) used in the present study contained both the firefly luciferase reporter gene and the internal control gene, Renilla luciferase. The pmiRGLO CDH3 3'-untranslated regions (3'-UTRs) wild-type (WT) vectors and pmiRGLO CDH3 3'-UTR mutated (MUT) vectors with the miR-665 binding sites replaced by a random nucleotide sequence were constructed. A 24-well plate was then used to seed AGS and HGC-27 cells $\left(2 \times 10^{5}\right.$ cells/well). The next step was the co-transfection of the cells with pmiRGLO CDH3-MUT or pmiRGLO CDH3-WT and with either miR-665 mimic or mimic-NC using Lipofectamine 3000 Transfection Reagent.
After collecting the cells transfected for $48 \mathrm{~h}$, Renilla luciferase and firefly luciferase activities were detected using the Dual Luciferase Reporter Assay System (Thermo Fisher Scientific, Inc.). Firefly luciferase activity was normalized to that of Renilla luciferase activity.

Statistical analysis. GraphPad Prism 7.0 (GraphPad Software, Inc.) was used for data analysis. To compare two variables in tissues, paired Student's t-test was utilized. To compare two groups in cell experiments, unpaired Student's t-test was used. To compare multiple groups, one-way ANOVA with Dunnett's or Tukey's post-hoc test was employed. Pearson correlation analysis was applied to assess the correlation between $\mathrm{CDH} 3$ and miR-665 expression. Fisher's exact test was used to determine the association between $\mathrm{CDH} 3$ expression and clinicopathological variables. Each experiment was performed thrice, and results were presented as the mean \pm standard error. $\mathrm{P}<0.05$ was considered to indicate a statistically significant difference.

\section{Results}

Identificationofkey genesinvolvedin GC. TwomRNAexpression profiles (GSE118916 and GSE79973) were downloaded from the GEO database. The profiles were then applied to filter the DEGs involved in GC. A total of 251 upregulated DEGs were overlapped between GSE79973 and GSE118916, with $\log \mathrm{FC}$ values $>1$ and adj. $\mathrm{P}<0.05$ (Fig. 1A). The 251 overlapped DEGs were uploaded to STRING for GO enrichment analysis (Fig. 1B). After performing GO enrichment analysis, 'cell adhesion' and 'regulation of cell population proliferation' were significantly enriched following GO analysis, and 16 genes were involved in these two biological processes (Fig. 1C). By using TCGA analysis, CDH3, COL18A1 and FAP were found to be significantly upregulated in GC samples compared with in non-tumor samples (Fig. 1D). To identify and investigate these key genes, the expression levels of CDH3, COL18A1 and FAP were further detected in clinical tissues, revealing that they were all upregulated in tumor tissues compared with in normal tissues (Fig. 1E-G). Since CDH3 exhibited the highest upregulation, it was selected to be further explored in subsequent experiments. 
A

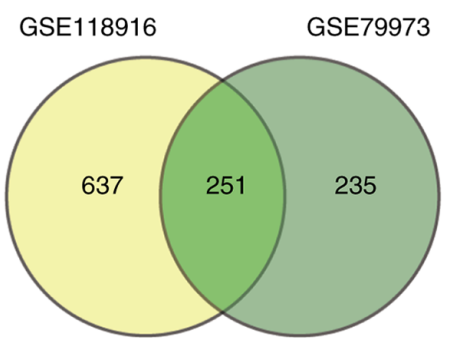

C

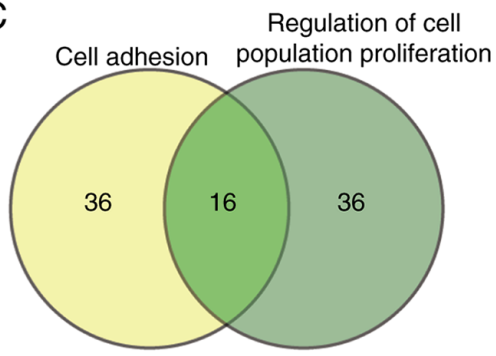

B

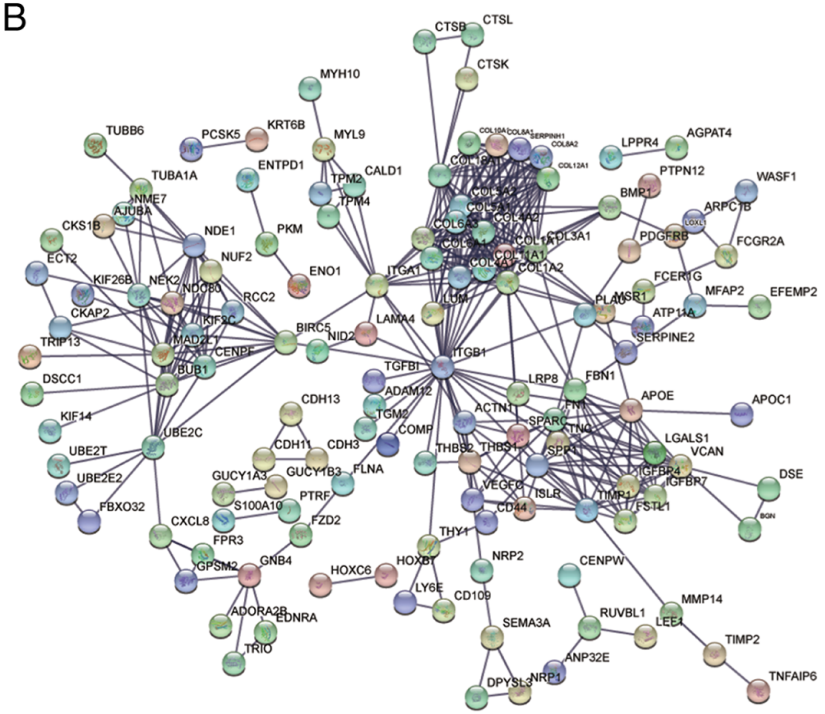

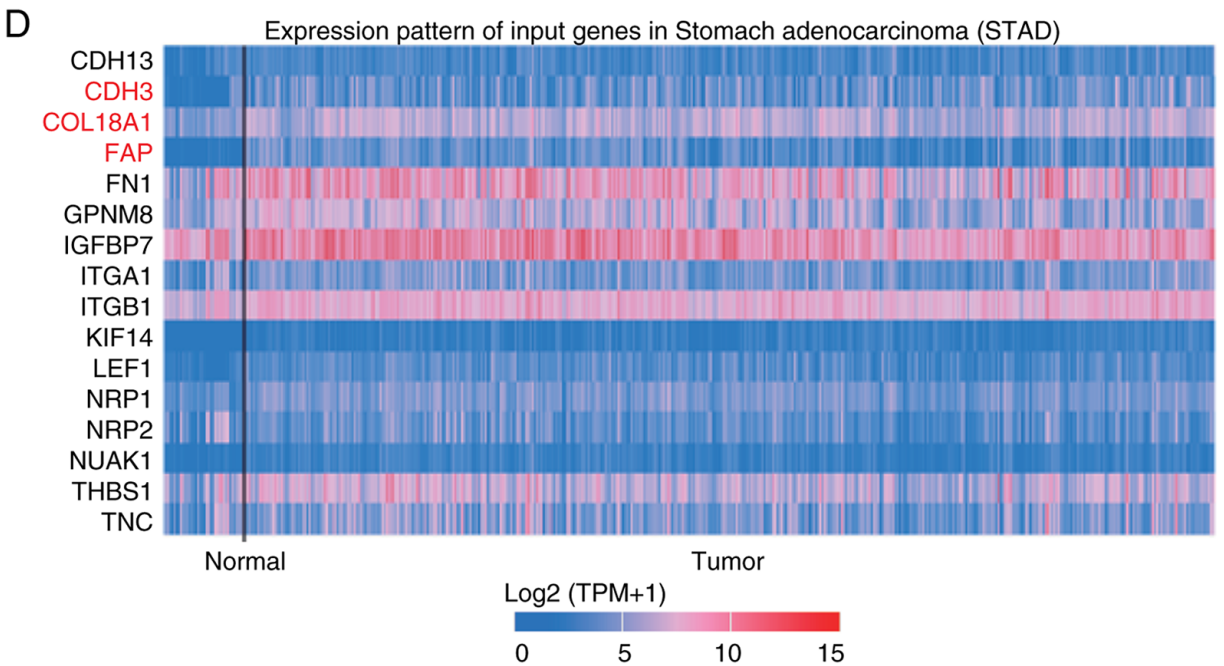
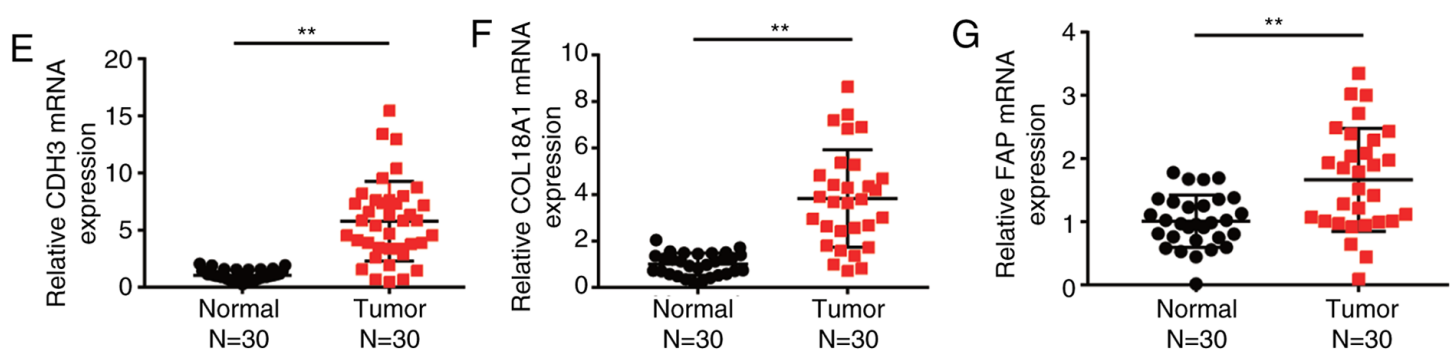

Figure 1. CDH3 is a key gene in GC. (A) A total of 251 upregulated differentially expressed genes overlapped between GSE118916 and GSE79973 mRNA expression profiles. (B) Gene Ontology enrichment analysis of the 251 upregulated genes was performed using STRING. (C) A total of 16 genes were involved in 'cell adhesion' and 'regulation of cell population proliferation' according to STRING analysis. (D) High CDH3, COL18A1 and FAP expression was observed in tumor tissues based on TCGA database. The blue and red colors in TCGA database represent low and high expression, respectively. Reverse transcription-quantitative PCR detection of the expression levels of (E) CDH3, (F) COL18A1 and (G) FAP in collected GC and adjacent normal tissues (n=30). Data are presented as the mean $\pm \mathrm{SD}$, and at least three independent tests were performed per experiment. ${ }^{* *} \mathrm{P}<0.001$. GC, gastric cancer; $\mathrm{CDH} 3$, cadherin 3; COL18A1, collagen type XVIII $\alpha 1$ chain; FAP, fibroblast activation protein; TCGA, The Cancer Genome Atlas.

CDH3 expression is increased in GC cells. The association between $\mathrm{CDH} 3$ expression and clinical features in patients with $\mathrm{GC}$ was then analyzed. CDH3 expression was associated with tumor size, histological grade, TNM stage and advanced lymph nodes status (Table SI). However, CDH3 expression was not associated with other clinicopathological features, such as age, sex, differentiation, smoking, drinking alcohol and $H$. pylori infection. Furthermore, the expression levels of $\mathrm{CDH} 3$ were confirmed in the gastric epithelial cells (GES-1) and the gastric adenocarcinoma cells (AGS, MKN74, GTL-16 and HGC-27). CDH3 expression was significantly increased in all GC cells compared with in GES-1 cells (Fig. 2A). Western blotting was employed to analyze $\mathrm{CDH} 3$ protein expression. Consistent with gene expression, $\mathrm{CDH} 3$ protein expression in 
A
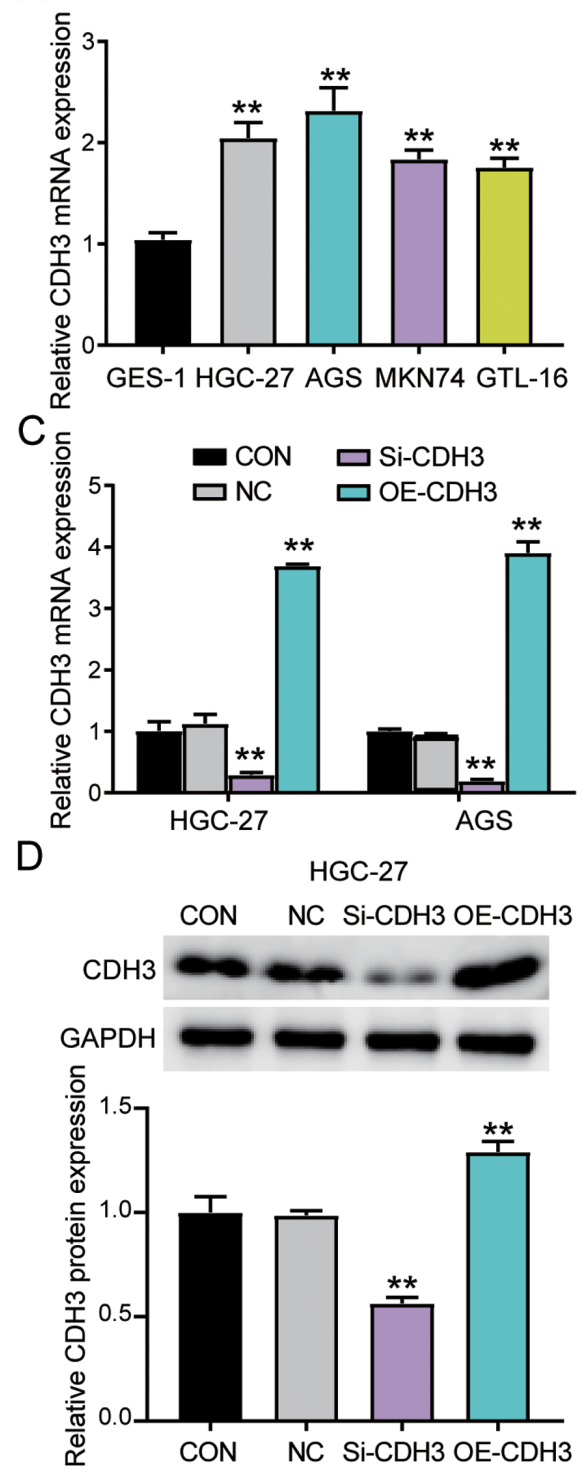

B
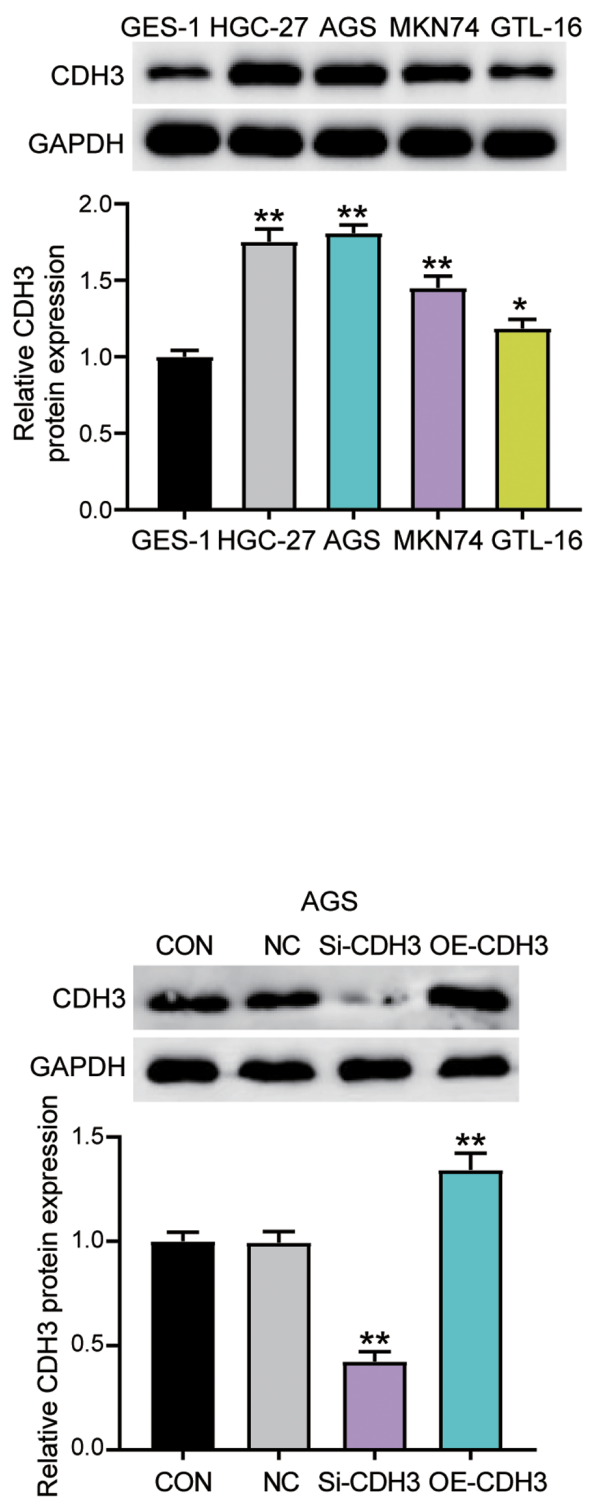

Figure 2. Upregulation of CDH3 expression in GC cells. (A) RT-qPCR detection of CDH3 mRNA expression in gastric epithelial cells (GES-1) and gastric adenocarcinoma cell lines (AGS, MKN74, GTL-16 and HGC-27). ${ }^{* *} \mathrm{P}<0.001$ vs. GES-1 cells. (B) Measurement of CDH3 protein expression in GES-1, AGS, MKN74, GTL-16 and HGC-27 cell lines via western blotting. ${ }^{*} \mathrm{P}<0.05$ and ${ }^{* * *} \mathrm{P}<0.001$ vs. GES-1 cells. (C) CDH3 mRNA expression was identified using RT-qPCR in HGC-27 and AGS cells transfected with Si-CDH3 or OE-CDH3. ${ }^{* *} \mathrm{P}<0.001$ vs. NC (D) CDH3 protein expression was confirmed via western blotting in HGC-27 and AGS cells transfected with $\mathrm{Si}-\mathrm{CDH} 3$ or OE-CDH3. Data are presented as the mean $\pm \mathrm{SD}(\mathrm{n}=3)$, and at least three independent tests were performed for every experiment. " $\mathrm{P}<0.001$ vs. $\mathrm{NC}$. CDH3, cadherin 3; Si-CDH3, small interfering RNA-CDH3; OE-CDH3, overexpression-CDH3; CON, blank control; $\mathrm{NC}$, negative control of Si-CDH3 co-transfected with negative control of OE-CDH3; GC, gastric cancer; RT-qPCR, reverse transcription-quantitative PCR.

GC cells was significantly increased compared with in GES-1 cells (Fig. 2B). Since HGC-27 and AGS cell lines exhibited the highest $\mathrm{CDH} 3$ expression, they were selected to perform subsequent experiments. The transfection of si-CDH3 and OE-CDH3 in AGS and HGC-27 cells was performed to assess the function of $\mathrm{CDH} 3$ expression in $\mathrm{GC}$ cells. The transfection efficiency was confirmed using RT-qPCR and western blotting. The results revealed that overexpression of $\mathrm{CDH} 3$ led to a significant upregulation of $\mathrm{CDH} 3 \mathrm{mRNA}$ and protein expression, while si-CDH3 led to a significant downregulation of $\mathrm{CDH} 3 \mathrm{mRNA}$ and protein expression (Figs. S1 A, 2C and D).

CDH3 acts as an oncogene in GC cells. Several experiments were performed to explore the function of $\mathrm{CDH} 3$ in $\mathrm{GC}$ cells.
The MTT assay results indicated that the cells transfected with OE-CDH3 presented higher cell viability than control cells, while the cells transfected with si-CDH3 exhibited lower cell viability than control cells (Fig. 3A). The results of the BrdU ELISA assay revealed that the proliferation of cells transfected with OE-CDH3 increased by 2 -fold, while that of the cells transfected with si-CDH3 declined by $50 \%$ compared with control cells (Fig. 3B). The apoptosis level was ascertained using the Caspase-3 Activity Assay kit and Annexin V-FITC Apoptosis Detection kit (Fig. 3C and D). The results demonstrated that the apoptosis level and caspase 3 activity in cells transfected with si-CDH3 significantly increased compared with that in control cells, while there was a decrease in the apoptosis and caspase 3 activity of cells transfected with OE-CDH3 (Fig. 3C and D). Additionally, the adhesion ability 

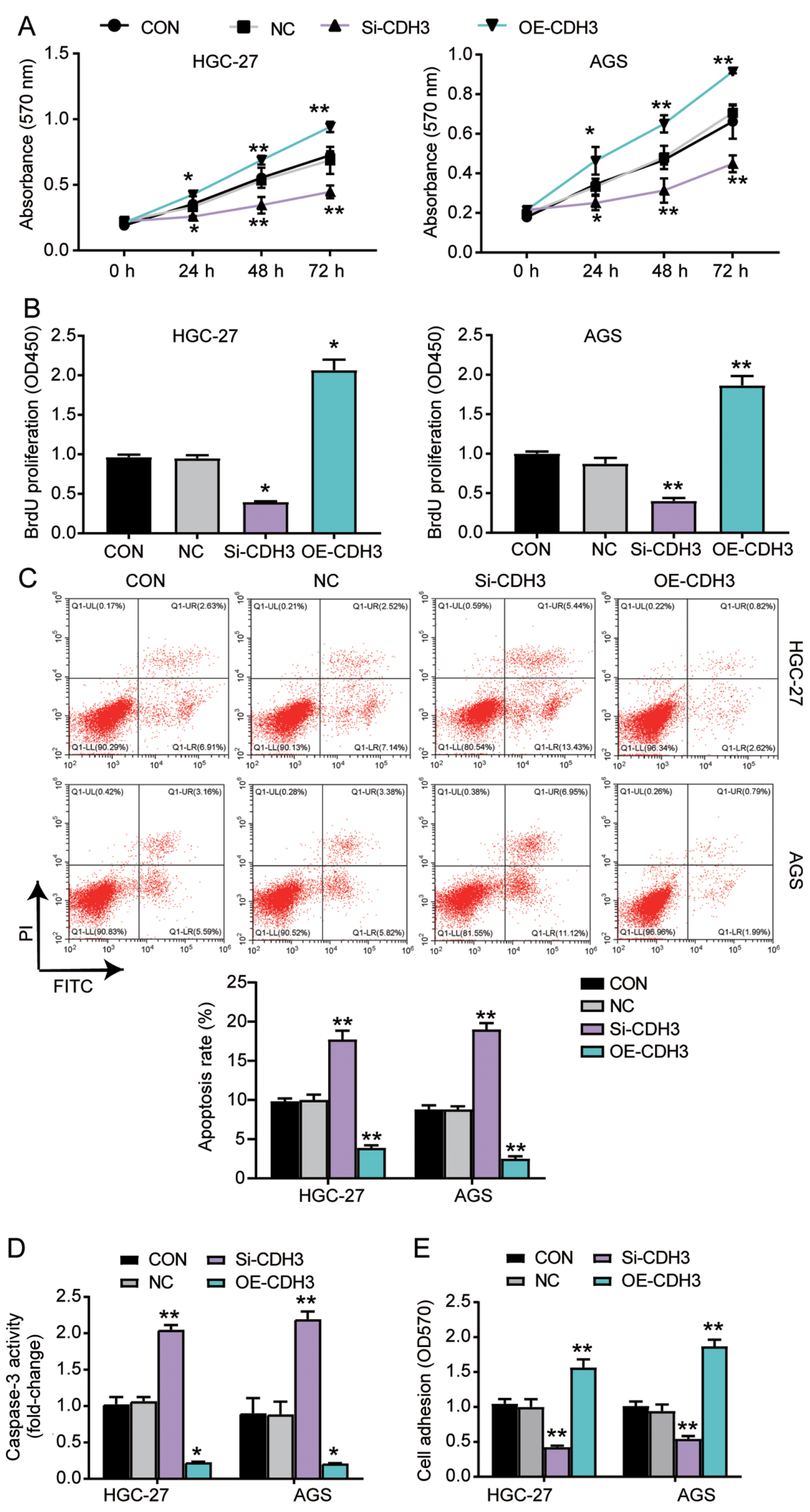

Figure 3. Overexpression of $\mathrm{CDH} 3$ enhances the viability, proliferation and adhesion, and represses the apoptosis of gastric cancer cells. (A) Cell viability was detected in AGS and HGC-27 cells transfected with OE-CDH3 or Si-CDH3 using the MTT assay. (B) Cell proliferation was ascertained in HGC-27 and AGS cells transfected with Si-CDH3 or OE-CDH3 by BrdU ELISA assay. (C) Apoptosis was determined in AGS and HGC-27 cells transfected with Si-CDH3 or OE-CDH3 using the FITC apoptosis detection kit. (D) Apoptosis was established in HGC-27 and AGS cells transfected with Si-CDH3 or OE-CDH3 by caspase activity assay kit. (E) Cell adhesion was detected in HGC-27 and AGS cells transfected with Si-CDH3 or OE-CDH3 using a cell adhesion assay kit. Data are presented as the mean $\pm \mathrm{SD}(\mathrm{n}=3)$, and at least three independent tests were performed for each experiment. ${ }^{*} \mathrm{P}<0.05$ and ${ }^{* *} \mathrm{P}<0.001 \mathrm{vs}$. NC. CDH3, cadherin 3; Si-CDH3, small interfering RNA-CDH3; OE-CDH3, overexpression-CDH3; CON, blank control; NC, negative control of Si-CDH3 co-transfected with negative control of $\mathrm{OE}-\mathrm{CDH} 3$; OD, optical density. 
of the OE-CDH3 group exhibited a $>1.5$-fold increase, while that of cells transfected with si-CDH3 decreased by $50 \%$ compared with control cells (Fig. 3E). Overall, the present results suggested that the overexpression of $\mathrm{CDH} 3$ enhanced the adhesion and proliferation of GC cells, but inhibited the apoptosis of GC cells.

miR-665 targets the CDH3 3'-UTR in GC. The GSE93415 profile was obtained from the GEO database and was used to screen the downregulated differentially expressed miRNAs with $\log \mathrm{FC}<-1$ and adj. $\mathrm{P}<0.05$. TargetScan and starBase were used to predict the miRNAs binding to the CDH3 3'-UTR. Venny 2.1.0 analysis indicated an overlap of hsa-miR-665 (Fig. 4A). The TargetScan results revealed that miR-665 matched the position 593-599 of the CDH3 3'-UTR (Fig. 4B). Next, the luciferase activity detected in AGS and HGC-27 cells confirmed that the miR-665 mimic in the CDH3-WT group downregulated the luciferase activity by $60 \%$ compared with cells transfected with the mimic-NC; in contrast to the $\mathrm{CDH} 3-\mathrm{WT}$ cells, miR-665 mimic had no significant effect on the cells in the CDH3-MUT group (Fig. 4C). Additionally, miR-665 expression was decreased by $60 \%$ in tumor tissues compared with in adjacent non-tumor tissues (Fig. 4D). Furthermore, an inverse correlation was detected between $\mathrm{CDH} 3$ and miR-665 expression in GC tissues (Fig. 4E). miR-665 expression was also analyzed in GC cells, revealing that miR-665 expression in AGS and HGC-27 GC cells was decreased by $50 \%$ compared with that in GES-1 cells (Fig. 4F). After transfection, miR-665 expression in the cells transfected with the miR-665 mimic increased by 4 -fold, while it decreased by $80 \%$ in the cells transfected with the miR-665 inhibitor compared with in the cells in the control group (Figs. S1B and 4G). Western blot analysis indicated that $\mathrm{CDH} 3$ protein expression in the miR-665 inhibitor-transfected cells was significantly increased, while it was significantly decreased in the cells transfected with the miR-665 mimic (Fig. 4H). Overall, these results indicated that by targeting $\mathrm{CDH} 3 \mathrm{mRNA}$, miR-665 regulated GC cells.

miR-665 targeting $C D H 3$ inhibits $G C$ progression. MTT assay were performed to study the function of miR-665 in GC cells. The results indicated that the cells transfected with the miR-665 inhibitor exhibited enhanced cell viability; additionally, the miR-665 inhibitor could reverse the suppressive effect of si-CDH3 on cell viability (Fig. 5A). Additionally, the results of the BrdU ELISA assay revealed a 2-fold increase in the proliferation of the cells transfected with the miR-665 inhibitor, and the miR-665 inhibitor reversed the suppressive effect of si-CDH3 on cell proliferation (Fig. 5B). The apoptosis level was identified using the two aforementioned kits, and the results indicated that apoptosis was suppressed by the miR-665 inhibitor, while the apoptosis in the group co-transfected with si-CDH3 and miR-665 inhibitor was similar to that in the control group (Fig. 5C and D). The cells transfected with the miR-665 inhibitor also exhibited a 1.5-fold increase in cell adhesion, and the negative effect of si-CDH3 on cell adhesion was relieved by the miR-665 inhibitor (Fig. 5E). Overall, the current results suggested that by targeting $\mathrm{CDH} 3$, miR-665 could inhibit cell proliferation and adhesion, but promote the apoptosis of GC cells.

\section{Discussion}

The present study confirmed the upregulation of $\mathrm{CDH} 3$ expression and the downregulation of miR-665 expression in GC tissues and cell lines. The overexpression of $\mathrm{CDH} 3$ increased cell proliferation and adhesion levels, and decreased the apoptosis level. On the other hand, the miR-665 mimic restrained the proliferation and adhesion of $\mathrm{GC}$ cells, and promoted their apoptosis. Moreover, $\mathrm{CDH} 3$ seemed to be a direct target of miR-665 in GC cells, meaning that miR-665 may inhibit $\mathrm{CDH} 3$ expression to suppress the progression of GC.

In the last three decades, several studies have reported the ability of $\mathrm{CDH} 3$ to accelerate the growth of multiple types of cancer, including lung (27), esophageal (9), colorectal (7) and breast cancer (28). A previous study has also suggested the involvement of $\mathrm{CDH} 3$ in promoting the motility of pancreatic cancer cells by activating Rho-family GTPases (8). Another study revealed that $\mathrm{CDH} 3$ upregulation associated with $\mathrm{CDH} 3$ promoter hypomethylation significantly influenced the proliferation of breast cancer cells (29). Moreover, in some studies, $\mathrm{CDH} 3$ expression was upregulated in GC cells $(11,12)$. The detection of the $\mathrm{CDH} 3$ demethylation level in 36 primary gastric carcinoma samples revealed that 25/36 (69\%) samples had an abnormal demethylation level, which may result in the promotion of gastric carcinoma (11). Another study reported the upregulation of $\mathrm{CDH} 3$ expression in 20/28 (71\%) GC tissues based on a cDNA microarray, and immunohistochemical analyses further confirmed an increase in $\mathrm{CDH} 3$ protein expression in GC tissues (12). Consistent with the aforementioned studies, the present study demonstrated that upregulated $\mathrm{CDH} 3$ expression in GC tissues and cells augmented cell proliferation and adhesion, and decreased apoptosis.

Furthermore, miR-665 has been associated with numerous human malignancies, including pancreatic (17), breast (18), cervical (30) and ovarian cancer (31). Previous studies indicated that this miRNA could promote the occurrence of cancer, as well as suppress cancer. For instance, by targeting Homeobox Protein Hox-A10, miR-665 inhibited the progression of ovarian cancer (19). Additionally, miR-665 sponged by RHPN1 Antisense RNA 1 suppressed tumor development by preventing the activation of AKT3 (32). Nonetheless, miR-665 could facilitate the tumorigenesis of ovarian cancer cells by targeting SRC Kinase Signaling Inhibitor 1 (31). In addition, miR-665 overexpression enhanced the proliferation, migration and invasion of non-small cell lung cancer cells (16). Regarding GC, miR-665 has been documented in several studies to suppress the progression of GC $(20,33)$. After binding to Protein Phosphatase 2 Regulatory Subunit $\mathrm{B} \alpha$, this miRNA inhibited the proliferation, invasion and epithelial-mesenchymal transition (EMT) of GC cells (20). In addition, miR-665 attached to AKT3 suppressed GC cells by decreasing proliferation and increasing apoptosis. Additionally, miR-665 was observed to be a target of LINC00565, which accelerated the development of GC by upregulating AKT3 expression (33). However, by inhibiting its target gene suppressor of cytokine signaling 3 (SOCS3), miR-665 promoted the EMT of gastric adenocarcinoma cells (21). In the present study, miR-665 binding to $\mathrm{CDH} 3$ inhibited cell proliferation and adhesion, but enhanced apoptosis in GC cells. 


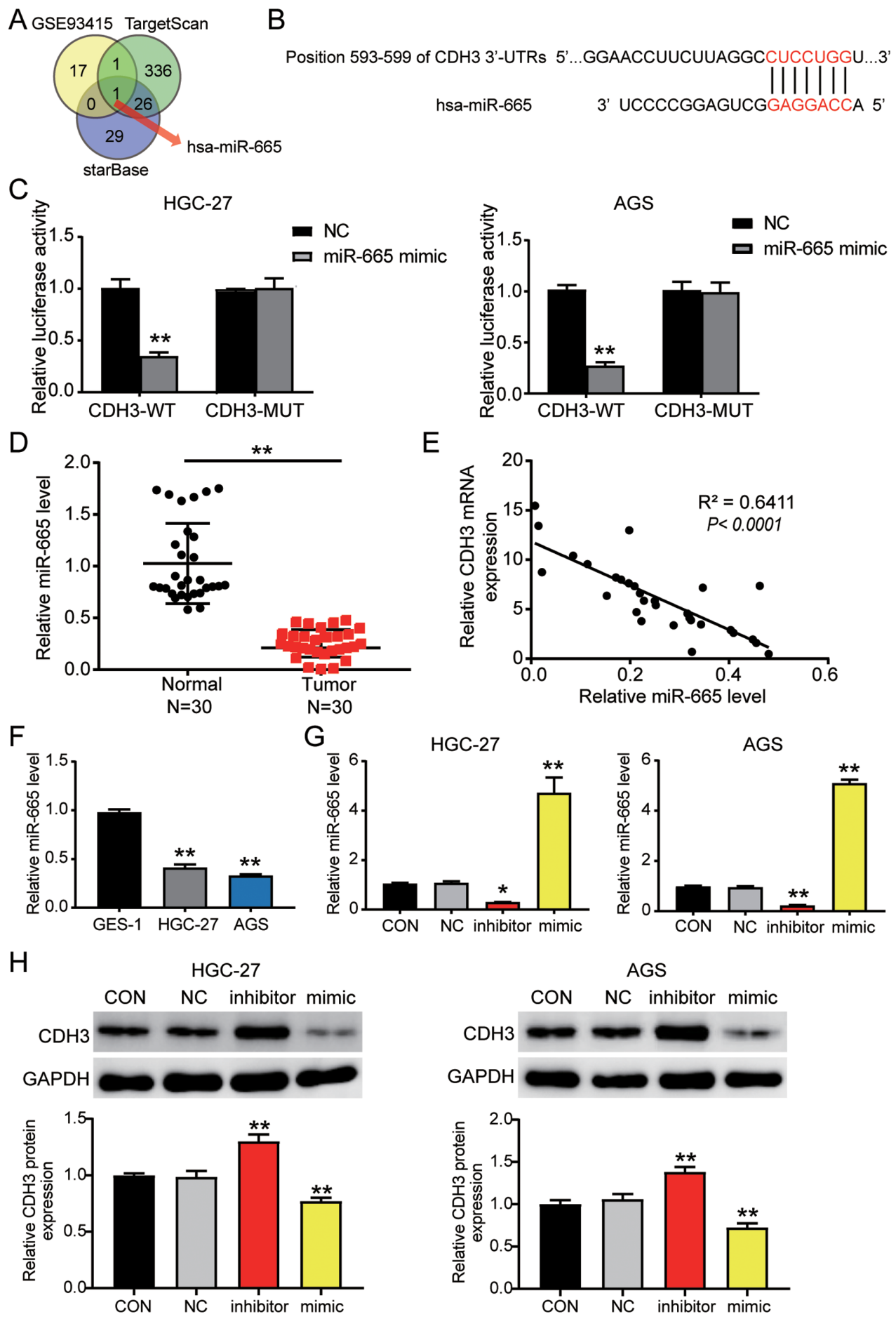

Figure 4. CDH3 is a candidate target gene of miR-665. (A) miR-665 was identified by Venny 2.1.0 analysis. TargetScan and starBase were employed to ascertain the miRNAs binding to CDH3. GSE93415 was used to identify the miRNAs with low expression in GC. (B) TargetScan revealed the predicted binding sequences of CDH3 3'-UTR. (C) Dual luciferase assay kit was utilized in CDH3-WT and CDH3-MUT cells transfected with NC or miR-665 mimic. " P $<0.001$ vs. NC. (D) RT-qPCR was used to identify miR-665 expression in $\mathrm{GC}$ and adjacent normal tissues $(\mathrm{n}=30)$. ${ }^{* *} \mathrm{P}<0.001$. (E) Pearson's correlation analysis revealed the negative correlation between CDH3 and miR-665 expression in GC samples. RT-qPCR was used to detect the expression levels of miR-665 in (F) GES-1, HGC-27 and AGS cells, and (G) AGS and HGC-27 cells transfected with miR-665 inhibitor or miR-665 mimic. (H) Measurement of CDH3 protein expression in HGC-27 and AGS cells transfected with miR-665 inhibitor or miR-665 mimic. Data are presented as the mean \pm SD $(n=3)$, and at least three independent tests were performed for every experiment. ${ }^{*} \mathrm{P}<0.05$ and ${ }^{* *} \mathrm{P}<0.001$ vs. NC. CDH3, cadherin 3; miR/miRNA, microRNA; WT, wild-type; MUT, mutant; CON, blank control; NC, negative control of miR-665 inhibitor co-transfected with negative control of miR-665 mimic; UTR, untranslated region; RT-qPCR, reverse transcription-quantitative PCR; GC, gastric cancer.

A single miRNA may have a number of targets (34). More specifically, miR-665 is involved in numerous pathways involved in GC, since it can target AKT3 (33), Yes-associated protein 1 (YAP1) (35), cysteine-rich transmembrane bone morphogenetic protein regulator 1 (CRIM1) (36) and SOCS3 (21). However, in the current study, the effect of miR-665 on AKT3, YAP1, CRIM1 and SOCS3 was not explored. While the current study has investigated the proliferation, adhesion 

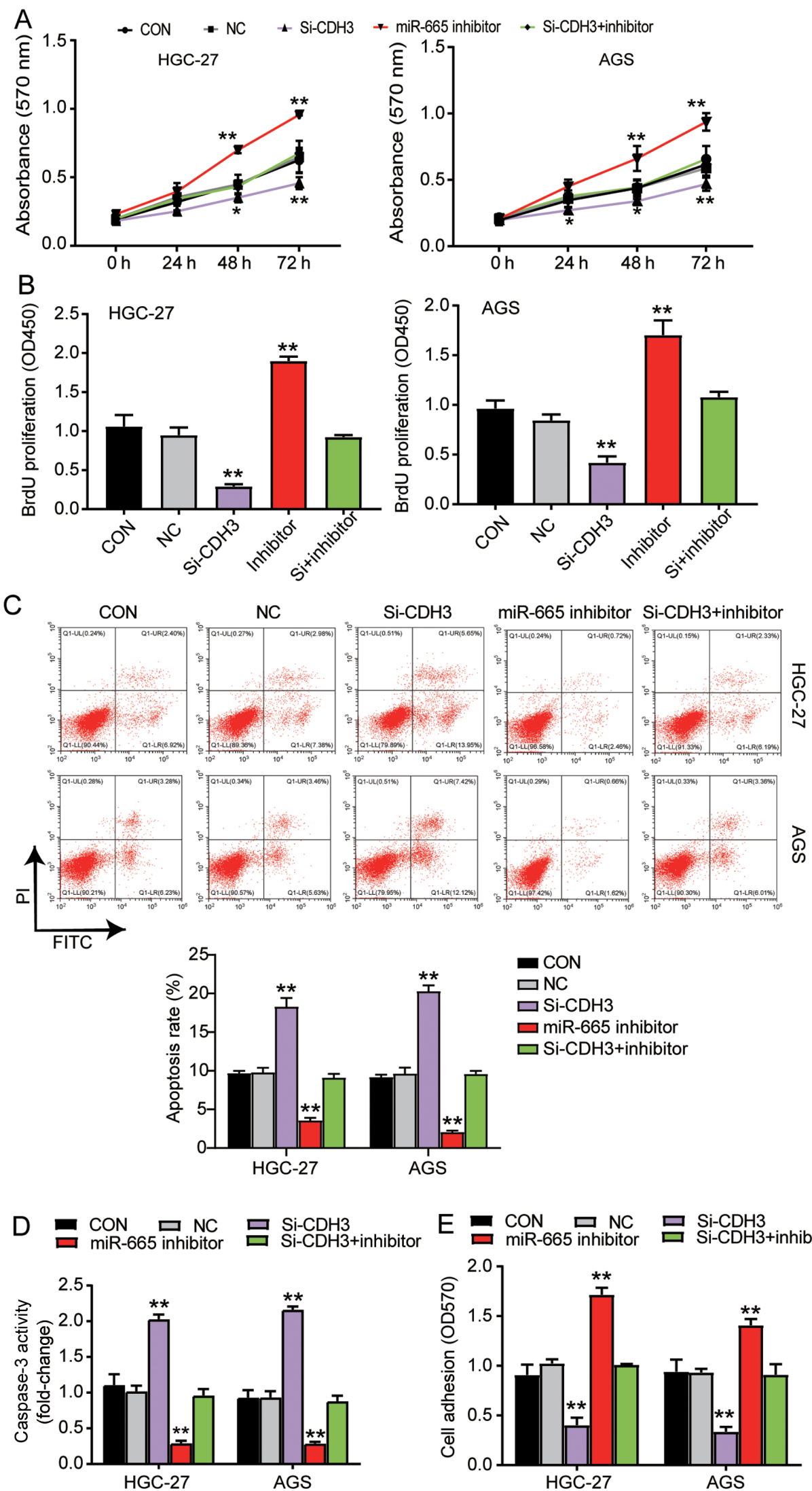

Figure 5. miR-665 targeting CDH3 inhibits proliferation and adhesion, and promotes apoptosis of gastric cancer cells. (A) Cell viability was ascertained in AGS and HGC-27 cells transfected with Si-CDH3, miR-665 inhibitor or Si-CDH3+miR-665 inhibitor by MTT assay. (B) Cell proliferation was analyzed in AGS and HGC-27 cells transfected with Si-CDH3, miR-665 inhibitor or Si-CDH3+miR-665 inhibitor by BrdU ELISA assay. Apoptosis was confirmed in AGS and HGC-27 cells transfected with Si-CDH3, miR-665 inhibitor or Si-CDH3+miR-665 inhibitor by (C) FITC apoptosis detection kit and (D) caspase-3 activity assay kit. (E) Cell adhesion was detected in HGC-27 and AGS cells transfected with miR-665 inhibitor, Si-CDH3 or Si-CDH3+miR-665 inhibitor using a cell adhesion assay kit. Data are presented as the mean $\pm \mathrm{SD}$, and at least three independent tests were performed for every experiment. "P<0.05 and ${ }^{* *} \mathrm{P}<0.001$ vs. NC. CDH3, cadherin 3; miR, microRNA; Si-CDH3, small interfering RNA-CDH3; CON, blank control; NC, negative control of miR-665 inhibitor co-transfected with negative control of Si-CDH3; OD, optical density. 
and apoptosis of GC cells, it is important to note that cancer occurrence is a complicated pathway interaction. The present study only confirmed the association between miR-665 and $\mathrm{CDH} 3$ in GC cells by analyzing the enrichment of target genes, so the lack of miRNA enrichment analysis and of survival analysis on the target genes and associated miRNAs are the other major limitations of the study. In the future, the potential signaling pathways and survival analysis of the target genes and associated miRNAs in GC should be further explored. Additionally, the current study only observed tumor characteristics at the cellular level. However, further studies are required to verify the current findings in animal models.

In conclusion, to the best of our knowledge, the present study was the first to demonstrate an interaction between miR-665 and CDH3, and to reveal that miR-665 may suppress the progression of $\mathrm{GC}$ by targeting $\mathrm{CDH} 3$. The present findings may offer further insight into the prognosis and treatment of GC.

\section{Acknowledgements}

Not applicable.

\section{Funding}

The present study was supported by Basic and Frontier projects of Science and Technology Department of Henan Province (grant no. 142300410050), Joint project of Henan Provincial Health and Family Planning Commission (grant no. 20170123), Henan Health and Family Planning Research and Innovation Talent Project (grant no. 51282) and Joint project of the National Natural Science Foundation of China (grant no. U1604174).

\section{Availability of data and materials}

The datasets used and/or analyzed during the current study are available from the corresponding author on reasonable request. The datasets generated and/or analyzed during the current study are available in the Gene Expression Omnibus database (https://www.ncbi.nlm.nih.gov/gds/?term=).

\section{Authors' contributions}

$\mathrm{XF}$ and SD performed the experiments and data analysis. YB and LZ conceived and designed the study. LZ and SD assessed the raw data to ensure its legitimacy. XF reviewed and edited the manuscript. All authors read and approved the final manuscript.

\section{Ethics approval and consent to participate}

The present study was approved by the Ethics Committee of Henan Provincial People's Hospital (Zhengzhou, China; approval no. 2019-04). All patients signed written informed consent.

\section{Patient consent for publication}

Not applicable.

\section{Competing interests}

The authors declare that they have no competing interests.

\section{References}

1. Bray F, Ferlay J, Soerjomataram I, Siegel RL, Torre LA and Jemal A: Global cancer statistics 2018: GLOBOCAN estimates of incidence and mortality worldwide for 36 cancers in 185 countries. CA Cancer J Clin 68: 394-424, 2018.

2. Wang F,Meng W, Wang B andQiaoL: Helicobacterpylori-induced gastric inflammation and gastric cancer. Cancer Lett 345: 196-202, 2014.

3. Dong $J$ and Thrift AP: Alcohol, smoking and risk of oesophago-gastric cancer. Best Pract Res Clin Gastroenterol 31: 509-517, 2017.

4. Marin JJ, Al-Abdulla R, Lozano E, Briz O, Bujanda L, Banales JM and Macias RI: Mechanisms of resistance to chemotherapy in gastric cancer. Anticancer Agents Med Chem 16: 318-334, 2016.

5. Biagioni A, Skalamera I, Peri S, Schiavone N, Cianchi F, Giommoni E, Magnelli L and Papucci L: Update on gastric cancer treatments and gene therapies. Cancer Metastasis Rev 38: 537-548, 2019.

6. Sprecher E, Bergman R, Richard G, Lurie R, Shalev S, Petronius D, Shalata A, Anbinder Y, Leibu R, Perlman I, et al: Hypotrichosis with juvenile macular dystrophy is caused by a mutation in CDH3, encoding P-cadherin. Nat Genet 29: 134-136, 2001.

7. Kumara HMCS, Bellini GA, Caballero OL, Herath SAC, Su T, Ahmed A, Njoh L, Cekic V and Whelan RL: P-Cadherin (CDH3) is overexpressed in colorectal tumors and has potential as a serum marker for colorectal cancer monitoring. Oncoscience 4: 139-147, 2017.

8. Taniuchi K, Nakagawa H, Hosokawa M, Nakamura T, Eguchi H, Ohigashi H, Ishikawa O, Katagiri $\mathrm{T}$ and Nakamura Y: Overexpressed P-cadherin/CDH3 promotes motility of pancreatic cancer cells by interacting with p120ctn and activating rho-family GTPases. Cancer Res 65: 3092-3099, 2005.

9. Liu D, Wu K, Yang Y, Zhu D, Zhang C and Zhao S: Long noncoding RNA ADAMTS9-AS2 suppresses the progression of esophageal cancer by mediating $\mathrm{CDH} 3$ promoter methylation. Mol Carcinog 59: 32-44, 2020.

10. Albergaria A, Ribeiro AS, Pinho S, Milanezi F, Carneiro V, Sousa B, Sousa S, Oliveira C, Machado JC, Seruca R, et al: ICI 182,780 induces P-cadherin overexpression in breast cancer cells through chromatin remodelling at the promoter level: A role for C/EBPbeta in CDH3 gene activation. Hum Mol Genet 19: 2554-2566, 2010.

11. Hibi K, Kitamura YH, Mizukami H, Goto T, Sakuraba K, Sakata M, Saito M, Ishibashi K, Kigawa G, Nemoto H and Sanada Y: Frequent CDH3 demethylation in advanced gastric carcinoma. Anticancer Res 29: 3945-3947, 2009.

12. Imai K, Hirata S, Irie A, Senju S, Ikuta Y, Yokomine K, Harao M, Inoue $\mathrm{M}$, Tsunoda $\mathrm{T}$, Nakatsuru $\mathrm{S}$, et al: Identification of a novel tumor-associated antigen, cadherin $3 / \mathrm{P}$-cadherin, as a possible target for immunotherapy of pancreatic, gastric, and colorectal cancers. Clin Cancer Res 14: 6487-6495, 2008.

13. Bartel DP: MicroRNAs: Genomics, biogenesis, mechanism, and function. Cell 116: 281-297, 2004.

14. Hornstein E, Mansfield JH, Yekta S, Hu JK, Harfe BD, McManus MT, Baskerville S, Bartel DP and Tabin CJ: The microRNA miR-196 acts upstream of Hoxb8 and Shh in limb development. Nature 438: 671-674, 2005.

15. Boehm M and Slack FJ: MicroRNA control of lifespan and metabolism. Cell Cycle 5: 837-840, 2006.

16. Xia J, Li D, Zhu X, Xia W, Qi Z, Li G and Xu Q: Upregulated miR-665 expression independently predicts poor prognosis of lung cancer and facilitates tumor cell proliferation, migration and invasion. Oncol Lett 19: 3578-3586, 2020.

17. Zhou B, Guo W, Sun C, Zhang B and Zheng F: Linc00462 promotes pancreatic cancer invasiveness through the miR-665/TGFBR1-TGFBR2/SMAD2/3 pathway. Cell Death Dis 9: 706, 2018.

18. Zhao XG, Hu JY, Tang J, Yi W, Zhang MY, Deng R, Mai SJ, Weng NQ, Wang RQ, Liu J, et al: miR-665 expression predicts poor survival and promotes tumor metastasis by targeting NR4A3 in breast cancer. Cell Death Dis 10: 479, 2019. 
19. Liu J, Jiang Y, Wan Y, Zhou S, Thapa S and Cheng W: MicroRNA-665 suppresses the growth and migration of ovarian cancer cells by targeting HOXA10. Mol Med Rep 18: 2661-2668, 2018.

20. Zhang M, Wang S, Yi A and Qiao Y: microRNA-665 is down-regulated in gastric cancer and inhibits proliferation, invasion, and EMT by targeting PPP2R2A. Cell Biochem Funct 38: 409-418, 2020.

21. Tang H, Long Q, Zhuang K, Yan Y, Han K, Guo H and Lu X: miR-665 promotes the progression of gastric adenocarcinoma via elevating FAK activation through targeting SOCS3 and is negatively regulated by lncRNA MEG3. J Cell Physiol 235: 4709-4719, 2020.

22. Li L,Zhu Z,Zhao Y,Zhang Q, Wu X, Miao B, Cao J and Fei S: FN1, SPARC, and SERPINE1 are highly expressed and significantly related to a poor prognosis of gastric adenocarcinoma revealed by microarray and bioinformatics. Sci Rep 9: 7827, 2019.

23. Jin Y,He J, Du J,Zhang RX, Yao HB and Shao QS: Overexpression of HS6ST2 is associated with poor prognosis in patients with gastric cancer. Oncol Lett 14: 6191-6197, 2017.

24. Sobin LH and Compton CC: TNM seventh edition: What's new, what's changed: Communication from the International Union Against Cancer and the American Joint Committee on Cancer. Cancer 116: 5336-5339, 2010.

25. Livak KJ and Schmittgen TD: Analysis of relative gene expression data using real-time quantitative PCR and the 2(-Delta Delta C(T)) method. Methods 25: 402-408, 2001.

26. Sierzega M, Kaczor M, Kolodziejczyk P, Kulig J, Sanak M and Richter P: Evaluation of serum microRNA biomarkers for gastric cancer based on blood and tissue pools profiling: The importance of miR-21 and miR-331. Br J Cancer 117: 266-273, 2017.

27. Hsiao TF, Wang CL, Wu YC, Feng HP, Chiu YC, Lin HY, Liu KJ, Chang GC, Chien KY, Yu JS and Yu CJ: Integrative omics analysis reveals soluble cadherin-3 as a survival predictor and an early monitoring marker of EGFR tyrosine kinase inhibitor therapy in lung cancer. Clin Cancer Res 26: 3220-3229, 2020.

28. Albergaria A, Resende C, Nobre AR, Ribeiro AS, Sousa B, Machado JC, Seruca R, Paredes J and SchmittF: CCAAT/enhancer binding protein $\beta(\mathrm{C} / \mathrm{EBP} \beta)$ isoforms as transcriptional regulators of the pro-invasive $\mathrm{CDH} 3 / \mathrm{P}$-cadherin gene in human breast cancer cells. PLoS One 8: e55749, 2013.
29. Paredes J, Albergaria A, Oliveira JT, Jerónimo C, Milanezi F and Schmitt FC: P-cadherin overexpression is an indicator of clinical outcome in invasive breast carcinomas and is associated with $\mathrm{CDH} 3$ promoter hypomethylation. Clin Cancer Res 11: 5869-5877, 2005.

30. Cao L, Jin H, Zheng Y, Mao Y, Fu Z, Li X and Dong L: DANCR-mediated microRNA-665 regulates proliferation and metastasis of cervical cancer through the ERK/SMAD pathway. Cancer Sci 110: 913-925, 2019.

31. Zhou P, Xiong T, Yao L and Yuan J: MicroRNA-665 promotes the proliferation of ovarian cancer cells by targeting SRCIN1. Exp Ther Med 19: 1112-1120, 2020.

32. Zhao J, Yang T, Ji J, Zhao F, Li C and Han X: RHPN1-AS promotes cell proliferation and migration via miR-665/Akt3 in ovarian cancer. Cancer Gene Ther 28: 33-41, 2020.

33. Hu J, Ni G, Mao L, Xue X, Zhang J, Wu W, Zhang S, Zhao H, Ding L and Wang L: LINC00565 promotes proliferation and inhibits apoptosis of gastric cancer by targeting miR-665/AKT3 axis. Onco Targets Ther 12: 7865-7875, 2019.

34. Luo C, Tetteh PW, Merz PR, Dickes E, Abukiwan A, Hotz-Wagenblatt A, Holland-Cunz S, Sinnberg T, Schittek B, Schadendorf D, et al: miR-137 inhibits the invasion of melanoma cells through downregulation of multiple oncogenic target genes. J Invest Dermatol 133: 768-775, 2013.

35. Lin X, Huang C, Chen Z, Wang H and Zeng Y: CircRNA_100876 is upregulated in gastric cancer (GC) and promotes the GC cells growth, migration and invasion via miR-665/YAP1 signaling. Front Genet 11: 546275, 2020.

36. Wu KZ, Zhang CD, Zhang C, Pei JP and Dai DQ: miR-665 suppresses the epithelial-mesenchymal transition and progression of gastric cancer by targeting CRIM1. Cancer Manag Res 12: 3489-3501, 2020.

This work is licensed under a Creative Commons Attribution-NonCommercial-NoDerivatives 4.0 International (CC BY-NC-ND 4.0) License. 